\title{
Effects of Multisensory Cues, Self-Enhancing Imagery and Self Goal-Achievement Emotion on Purchase Intention
}

\author{
Nak-Hwan $\mathrm{CHOI}^{1}$, Xinxin QIAO ${ }^{2}$, Li WANG $^{3}$ \\ Received: July 12, 2019 Revised: October 19, 2019 Accepted: October 24, 2019
}

\begin{abstract}
This research aimed at studying the role of self-enhancing imagery and self goal-achievement emotion in the effect of characteristics perceived at advertisements using multisensory cues on purchase intention. Sports shoes advertisement was selected as an empirical research object. Questionnaire survey method was used to collect data. 'WenJuanXing' site was used to make the questionnaire in Chinese, and it was loaded on WeChat and QQ. 260 participants from different regions of China participated in online questionnaire survey. The results of testing the hypotheses by structural equation model in Amos 21.0 program are summarized as followings. The congruency between multisensory cues and self-discrepancy awareness positively evoked the self-enhancing imagery and the self goal-achievement emotion. The object relevance between the consumer and the product advertised did not induce the emotion, but evoked the self-enhancing imagery. Both of the self-enhancing imagery and the self goal-achievement emotion had positive effects on the product purchase intention. When developing advertisement, marketers should focus on multisensory cues' characteristics to enhance the self-enhancing imageries as well as to help feel the goal-achievement emotion. They should pay attention to the ways by which the multisensory cues' characteristics used to develop advertisement can be perceived to be congruent with each other by consumers.
\end{abstract}

Keywords : Multisensory Cues, Self-Enhancing Imagery, Self Goal-Achievement Emotion, Purchase Intention

JEL Classification Code : C83, L81, M31, P46

\section{Introduction}

How to attract consumers to buy products is becoming more and more important to marketers since consumers meet more and more opportunities of choosing product in today's competitive and changing business environment. Studies found external stimulation such as advertising can influence consumers' cognitions and emotions guiding purchase behaviors (Michon, Chebat \& Turley, 2005; Turley \& Milliman, 2000). Consumers compare the information

1 First Author, Professor, Department of Business Administration, Jeonbuk National University, Jeonju, Korea.

Tel: +82-63-270-2998, Email: cnh@jbnu.ac.kr

2 Master, Jeonbuk National University, Jeonju, Korea.

Email: 1125595700@qq.com

3 Corresponding Author, Doctoral Student, Jeonbuk National University, Jeonju, Korea. Email: 5613819@naver.com

(c) Copyright: Korean Distribution Science Association (KODISA)

This is an Open Access article distributed under the terms of the Creative Commons Attribution Non-Commercial License (http://Creativecommons.org/licenses/by-nc/4.0/) which permits unrestricted noncommercial use, distribution, and reproduction in any medium, provided the original work is properly cited. before making decision (Panwar, Anand, Ali \& Singal, 2019), especially at the stage of processing advertised brand information. Multisensory cues used in advertising might influence consumers' emotions and cognitions concerned with the product advertised (Hultén, 2012; Krishna, 2012; Choi, Zhang \& Chen, 2018). Advertisements' multisensory cues may have a positive impact on consumers' emotions and cognitions. Therefore, how to advance the various sensory cues to match emotions and cognitions inducing consumers' choice is crucial to marketers (Thapa, 2011). Particularly, since different multisensory cues reveal different influences on consumers, marketers should know how to differentiate the multisensory cues used for advertising their products.

According to gestalt principles, multisensory cues are perceived as a whole rather than as the sum of each individual component (Lin, 2004). The cues from different sensory modalities might be integrated to be not a simple accumulation of the effects of each modality, but the abstract whole different from the simple accumulation. 
There can be various non-linear interactions between the sensory modalities exposed to consumers (Driver \& Noesselt, 2008). The interaction effects of each modality are dynamically intertwined to show the multiplied sensory cooperation, or disambiguated effects that meaning of one cue is removing an ambiguity in other cues by which the multisensory cues can induce a certain whole meaning of the stimulation.

However, past research had mainly studied what kind of psychology the consumers will produce and how to make decision during their purchase process (Shah, Aziz, Jaffari, Waris, Ejaz, Fatima \& Sherazi, 2012), or when they would have the specific purchase target (Morinez, Kube, Santos, Da Costa \& Antranikian, 2007). There have been the studies about the role of haptic stimulation (Atakan, 2014), the effects of felt emotion on predicted social behavior (DeWall, Baumeister, Chester \& Bushman, 2016), effects of sensory marketing on judgment and behavior (Krishna, 2012), however, the existing research has not given much attention to discovering what kind of emotions and thoughts customers get at the exposure to multisensory cues of the advertisement to ultimately promote the purchase intention. Therefore, it is necessary to explore the characteristics of multisensory cues that could promote the purchase intention, and it is also necessary to find the emotions and thoughts that could mediate the effects of the multisensory cues on the intention.

The purposes of this research are established as follows. First, current research intends to explore which characteristics of multisensory cues used for advertising product can activate consumers' self-enhancing imagery and goal-achievement emotion. Second, this research will explore whether the self-enhancing imagery and the goalachievement emotion can promote purchase intention.

\section{Theoretical Background and Hypotheses}

\subsection{Self-Enhancing Imagery and Self Goal- Achievement Emotion}

\subsubsection{Self-Enhancing Imagery}

In accordance with goal systems theory (Fishbach, Friedman \& Kruglanski, 2003), the goal is actually a concrete manifestation of individuals' mental activity to affect their behaviors and motivations, which consists of motivational and cognitive aspect (Kruglanski, 1996). The motivational aspect means that the goal can motivate people to do something coming from their inside, while cognitive aspect is related to the points that the goals can be cognitively activated or primed by external stimulus (Bargh, 1997; Chartrand \& Bargh, 1996).

In the other hand, imagery is a process rather than a structure, which can be memorized through the process of collecting or processing information (MacInnis \& Price, 1987). Imagery plays a role in affecting affective responses to stimuli, and behavior (Rossiter \& Percy, 1978, 1983; Choi, Nguyen \& Teng, 2019). The process of forming imagery aims at finding sensory experience and perception of senses that exist in memory (Petrova \& Cialdini, 2008).

In view of the cognitive aspect of goals, self-goals can be activated by self-related external multisensory cues in advertisement to induce self-enhancing imagery, and in the motivational aspect of goals, self-enhancing imagery could promote the intent to purchase the product advertised. Selfenhancing imagery may increase the consumers' purchase intention. Enhancing self-imagery can promote purchase intentions (Schlosser, 2003; Shiv \& Huber, 2000). When consumers' self-enhancing imageries are aroused at product advertising, their purchase intention will be promoted.

H1: Self-enhancing imagery positively affects purchase intention.

\subsubsection{Self-Achievement Emotion}

Emotions are composed of many factors, including perception, behavior, and personal physiology (Scherer, 2000). Outcomes also generate emotions (Pekrun, 2006). In recent research, Pekrun (2006) found that when a person achieves a goal, the goal will have a significant impact on the person's emotions, and achievement goals can guide our behaviors (close or avoid) (Hulleman, Schrager, Bodmann \& Harackiewicz, 2010).

Self goal-achievement emotion is defined as the emotional perception that is generated when the goals are activated and expected to be achieved. There is a positive correlation between the positive goal and consumers' emotions (Jones, Reynolds \& Arnold, 2006). Jones (1999) demonstrates that each consumer has its own specific goals. When consumers achieve their own consumption goals and feel pride or happy in the goal achievement, then the product purchase intention might also be enhanced (Ratneshwar \& Morrin, 2000). The goal-achievement emotions could promote purchase intention. Therefore, we propose the hypothesis:

H2: Self goal-achievement emotions will positively affect purchase intention.

\subsection{Multisensory Cues}

\subsubsection{Meaning of Multisensory Cues}

Multisensory cues are composed of multiple single sensory cue. Single sensory cue includes five modalities: vision, auditory, olfactory, taste, and tactile. Individual's perception of external environment depends more on multisensory cues rather than on a single sensory cue. And sensory inputs from environments as specific odors, color, tone, and temperature can be intertwined with each other to generate reactions (Biggers \& Pryer, 1982; Franz, 2006).

The brain can often unconsciously integrate these sensory cues from the surrounding environment (Macpherson, 2011) to help consumers enhance a perception 
of stimuli (Helbig \& Ernst, 2008; Lalanne \& Lorenceau, 2004), through which the characteristics of the stimuli could be determined. And since there is an interaction between different sensory cues, one modality sense may have effect on another modality sense (Bresciani, Ernst, Drewing, Bouyer, Maury \& Kheddar, 2005; Seigneuric, Durand, Jiang, Baudouin \& Schaal, 2010).

In the other hand, purchase intentions refer to the possibility that consumers are willing to consider buying certain products or brands. Past research found that multisensory cues can awaken consumers' perception of the object and influence their purchase intention (Imschloss \& Kuehnl, 2017; Mattila \& Wirtz, 2001). The input of properly intertwined multisensory cues can enable consumers to better perceive products or better guide consumers' behavior (Turley \& Milliman, 2000).

In Table 1, there have been the past studies about multisensory advertising or approach, however, at multisensory cues of the advertisement, what kind of emotions and thoughts customers get to ultimately form the

purchase intention has not addressed in the existing research. The Table 1 explains the commons and differences between the past and this study.

\subsubsection{Characteristics of Multisensory Cues}

\subsubsection{Congruence among Multisensory Cues}

One of the characteristics of multisensory cues is congruence versus incongruence between the cues. Congruence is the degree of matching between the various sensory cues (Bone \& Ellen, 1999; Peracchio \& Tybout, 1996). And the congruence among different sensory modalities plays a positive role in making decision (Ludden, Schifferstein \& Hekkert, 2009). However, the incongruence among multisensory cues may induce emotional conflicts to negative impact on the decision making (Müller, Habel, Derntl, Schneider, Zilles, Turetsky \& Eickhoff, 2011).

Table 1: Commons and Differences between Previous Research and This Research

\begin{tabular}{|c|c|c|c|}
\hline Authors & Contents & Commons & Differences \\
\hline Krishna (2012) & $\begin{array}{l}\text { Sensory cues, perception, } \\
\text { judgement and behavior }\end{array}$ & $\begin{array}{l}\text { Sensory effects judgement and } \\
\text { behavior }\end{array}$ & $\begin{array}{l}\text { Multisensory cues influences } \\
\text { consumers purchase intention }\end{array}$ \\
\hline $\begin{array}{l}\text { Hulleman, Schrager, Bodmann, } \\
\text { \& Harachiewicz (2010) }\end{array}$ & $\begin{array}{l}\text { Achievement goals, emotions } \\
\text { and behaviors }\end{array}$ & $\begin{array}{l}\text { Achievement goals can impact } \\
\text { emotions and guide behaviors }\end{array}$ & $\begin{array}{l}\text { Multisensory cues can impact } \\
\text { consumers goal-achievement } \\
\text { emotion }\end{array}$ \\
\hline
\end{tabular}

Note: This Table 1 is built by authors' reviewing the past research

\subsubsection{Self-Discrepancy Awareness}

In the self-discrepancy theory, there are actual self, ideal self and ought self (Higgins, 1987). Actual self can represent how others think of you and how you see yourself according to your various real characteristics, intelligence, style of handling things; ought self is the representation of people's duty, responsibilities and obligations; ideal self can be seen as the hopes, wishes or aspirations from the eye of either yourself or others (Mason, Smith, Engwall, Lass, Mead, Sorby \& Wonderlich, 2019). When individual becomes aware of the discrepancy between actual self and ideal self, he or she may want to do something to reduce the gap between the actual self and ideal self, and his or her state of achieving the ideal self-goal may be activated at the same time (Orellana-Damacela, Tindale \& Suarez-Balcazar, 2000). The multisensory cues focused on enhancing consumers' self could lead them to perceive the gap between actual self and ideal self.

\subsubsection{Object Relevance between Consumer and Product Advertised}

Object relevance exists when certain characteristics of the consumers can match the characteristics of the product (Kleine, Kleine \& Kernan, 1993; Reed, 2004). And consumers have a tendency to choose products which can make them feel comfortable, satisfy their desires, and match their identity (Belk, 1988; Sirgy, 1982; Zinkhan \& Hong, 1991) or personalities (Holbrook, 1992). The object product should be consistent with consumers when the product's characteristics are consistent with the consumers' identity or status (Stokburger-Sauer, Ratneshwar \& Sen, 2012). The multisensory cues with the characteristics consistent with consumers' self could induce the object relevance between consumers and the product advertised.

\subsubsection{Characteristics of Multisensory Cues and Self- Enhancing Imagery}

When the multisensory cues in advertisement are congruent with each other, our impression to the products or brands advertised can be deepened, which in turn will enhance the imagery of the products or brands (Cheng, Wu \& Yen, 2009). Consumers are relatively easy to have a positive attitude towards the product or brand by which their goal is more likely to be activated. The congruence among 
self-related multisensory cues may increase self-enhancing imagery.

Self-discrepancy (Higgins, 1987) enables us to have a clear positioning. Because only when we have a clear picture of ourselves in the moment (actual self) and know what responsibilities we should undertake (ought self), we may know what our goals (ideal self) are. The clear positioning of the ideal self is more beneficial to activating the ideal self-goals, and more helpful to making efforts to enhance self-image.

In general, consumers have a tendency to choose products which are positively associated with their identity. When consumers see a product and find that some features of the product are consistent with their identities, consumers will deepen their positive impression to the product. So the degree of object relevance between products and consumers will have positive impact on forming self-enhancing imagery

Therefore, we propose the following hypotheses:

H3a: Congruence among sensory cues will induce selfenhancing imagery.

H3b: Self-discrepancy awareness will induce self-enhancing imagery.

H3c: Object relevance between consumer and product advertised will induce self-enhancing imagery.

\subsubsection{Characteristics of Multisensory Cues and Self} Goal-Achievement Emotion

Different sensory cues can cause different emotions. When the multisensory cues are congruent with each other, there could be the positive impact on the goal-achievement emotion. Individual is easy to feel positive emotions when the multisensory cues are congruent. Therefore, if selfrelated multisensory cues are congruent, it may have a positive effect on self goal-achievement emotions.

And self-discrepancy (Higgins, 1987) has an influence on emotions. Ideal self can make us have goals and pursue them. Due to the existence of self-discrepancy awareness, goals of decreasing the discrepancy are more likely to be activated. Therefore, self-discrepancy awareness from the self-related multisensory cues will have positive influence on the goal-achievement emotions.

The degree of object relevance between the product advertised and the customers could have an impact on consumer emotions. When the product has the symbolic characteristics that are consistent with customers, it will be more conducive to stimulating the customers' emotions (Wallendorf \& Arnould, 1988). The higher the relevance between products and consumers is, the stronger the consumers' emotions about products will be (Zinkhan \& Hong, 1991). We suggest that the object relevance between the products and consumers can enhance the self goalachievement emotions.

Therefore, we propose the following hypotheses:
H4a: Congruence among sensory cues will enhance self goal-achievement emotion.

H4b: Self-discrepancy awareness will enhance self goalachievement emotion.

H4c: Object relevance between consumer and product advertised will enhance self goal-achievement emotion.

In sum, all the hypotheses can be delineated by < Figure $1>$.

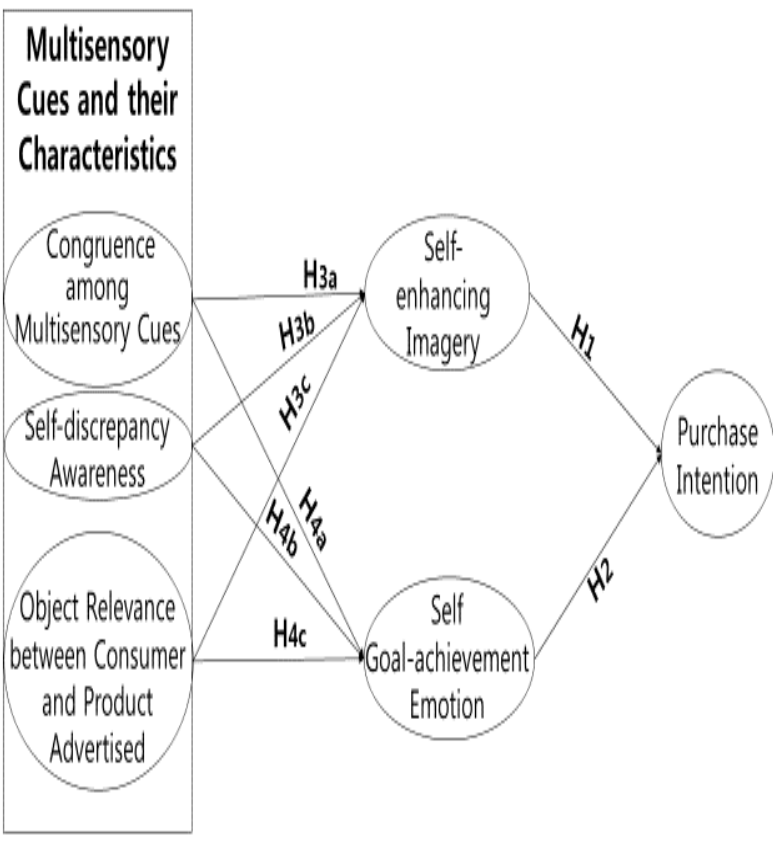

Figure 1: Research Model

\section{Empirical Study}

\subsection{Product Selection for Empirical Study}

In order to find which kind of the advertisement's multisensory cues can easily and quickly wake up participants' self-discrepancy, and help feel the object relevance, this study conducted a pretest. We selected 30 undergraduate participants and asked them to choose an answer by using the question "With the rapid development of contemporary society, more and more people want to have a healthy lifestyle to maintain a good shape. Which of the following methods would you choose to accomplish this goal?" The alternative answers include "1. Sports (sports shoes), 2. Low-calorie foods (vegetables), 3. No side-effect and weight loss products (meal replacement powder)." Finally, frequency analysis results showed that 21 participants chose the sports. Based on the result and the aim of this study, we decided to use sport shoes for empirical study. 


\subsection{Advertisement Development}

In the view of the aim of this study of demonstrating how the advertisements' multisensory cues influence consumers' purchase intention, we decided to use the short video of the sports shoes which consists of visual and auditory information. This short video tries to use the dynamic music and girl's soft but firm voice to evoke passion and bravery. The music cue which added to the short video should have a positive effect on stimulating consumers' perception. We chose the short video with dynamic music "Future Starts Slow" (https://v.qq.com/x/page/q0863fl7b9h.html), coming from the Google video. The melody is passionate, cheerful, light, and can bring the audience pleasure and positive emotions. Because dynamic music is more easily to stimulate people's passion for sports, we use this music at the short video. The dynamic music matches the dynamic elements of running, and the music could play an auxiliary effect in stimulating consumers' perception. And in order to strengthen the viewers' impression, four pictures are taken from screenshot of the existing short video which are just consistent with the subject of our questionnaire. Therefore, the four pictures were used as follows, the first with "keep running", the second with "make effort", the third with "Be better", and the fourth with "U can be better with the shoes" are shown in the questionnaire. Participants are asked to click https://v.qq.com/x/page/q0863fl7b9h.html to be exposed to the advertisement.

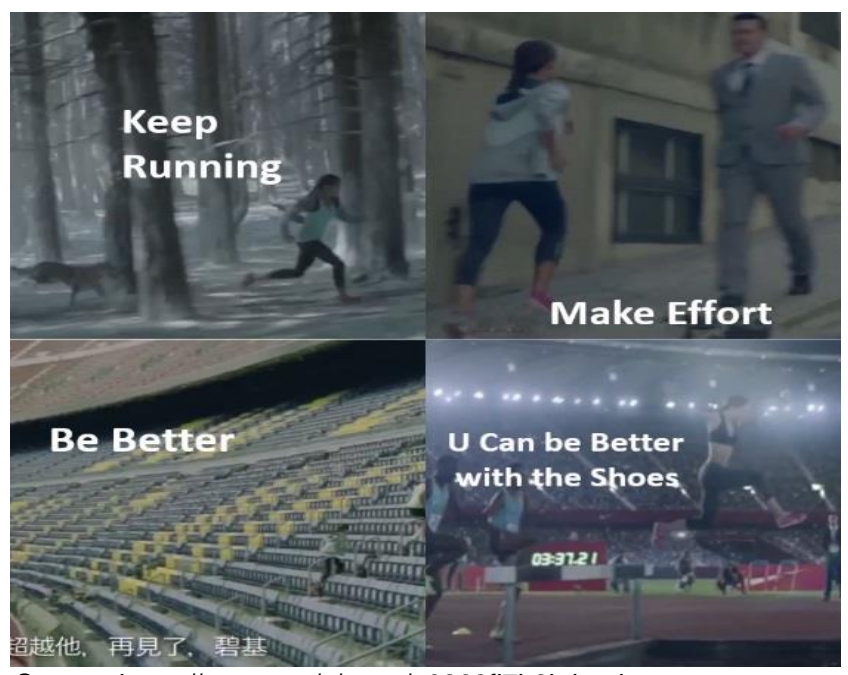

Source: https://v.qq.com/x/page/q0863fl7b9h.html

Figure 2: Research Advertisements

\subsection{Measures of Configuration Concepts}

After seeing the short video advertisement of this sports shoes and 4 screenshots, participants answer three questions to insure they received multisensory cues rather than the single cue at this advertising. These questions are "1. I sense the various color of this sports shoes advertisement." "2. I sense the soft tactility of this sports shoes advertisement." "3. I sense the dynamic melody sound in this sports shoes advertisement" using 7-point scales. These three questions were used to only check the multisensory characteristics of the advertisement not included in the research model. And we checked the level of paying their attention to this advertisement by using "I pay much attention to this sports shoes advertisement." on the 7point. So, this attention-related question and the three questions are not appeared in the Table 4.

\subsubsection{Measures of Congruence among Multisensory Cues (CMC)}

As we mentioned before, congruence can be defined as the degree of fit among all sensory cues of the stimulus (Bone \& Ellen, 1999; Peracchio \& Tybout, 1996). This research decided to use four items on 7-point scales $(1=$ not at all, $7=$ very much) to measure the congruence among multisensory cues. They are "1. All the visual, tactus and sound cues of this sports shoes advertisement are appropriate to each other." " 2 . All the visual, tactus and sound cues of this sports shoes advertisement fit with each other." "3. All the visual, tactus and sound cues of this sports shoes advertisement are consistent with each other." "4. I think all multisensory cues from this sports shoes advertisement are congruent with each other."

3.3.2. Measures of Self-Discrepancy Awareness (SDA)

To arouse participants' self-discrepancy, this research used the Self-Discrepancies Scales (S-DS) (Philippot, Dethier, Baeyens \& Bouvard, 2018). Firstly, participants are asked to think for a moment and then to use three features to complete three sentences. These three sentences are " 1 , I want to be..." "2. I should be..." "3. I am ..." We give some examples of possible features (for example, smart, hardworking, wise and so on) to help them complete the three sentences. Then we use 4 items to measure their selfdiscrepancy removal awareness. They are "1. Making effort can bring me closer to my ideal self." "2. I keep running to approach my ideal self." "3. I feel discrepancy between my actual self and ideal self." "4. I try to narrow this discrepancy between my actual self and ideal self" which are scored on 7-point scale (1=not at all, 7=very much).

\subsubsection{Measures of Object Relevance between Consumer and Product Advertised (RCP)}

To measure objective relevance between consumer and product advertised, based on identity similarity between brand or product and consumers (Kleine, Kleine \& Kernan, 1993; Reed, 2004), our research uses 5 items as followings "1. This pair of sports shoes' image is interconnected with my image." "2. This pair of sports shoes' image can be bundled to my image together." " 3 . This pair of sports shoes' image interacts with my ideal image." "4. This pair of sports shoes" image is similar to my image." "5. This pair of sports shoes is suitable for me" on a seven-point scale (1=not at all, $7=$ very much). 


\subsubsection{Measures of Self-Enhancing Imagery (SEI)}

As mentioned before, individual may draw imaginations based on the existing information when they are exposed to multisensory cues from environment (MacInnis \& Price, 1987), for example, advertisements. When individual's goals are activated at the exposure time, enhanced self-imagery may be formed. 4 items on 7-point scale ranging from $1=$ not at all, 7=very much are used to measure self-enhancing imagery. These items include " 1 . This advertisement makes me want to do something to enhance myself." "2. This advertisement helps me know how to enhance myself." "3. This advertisement makes me imagine that I'm getting stronger." "4. This advertisement makes me imagine that I'm enhancing myself."

\subsubsection{Measures of Self Goal-Achievement Emotion (SGAE)}

Researches have demonstrated individuals can feel positive emotions if goals generate positive effects while individuals can feel negative emotions if goals generate negative effects (Jones, Reynolds \& Arnold, 2006). More importantly, achievement goal theory (Dweck \& Elliot, 1988; Elliot \& Pekrun, 2007) shows achievement goals are consistent with achievement emotions. Therefore 4 items on the 7-point scale ranging are used to measure self goalachievement emotion. They are "1. I will feel pride if I can achieve my goal by using this sports shoes advertised." " 2 . I will feel exciting if I can complete my goal by using this sports shoes advertised." "3. I will feel confident if I can complete my goal by using this sports shoes advertised." "4. I will feel fulfilled if I can complete my goal by using this sports shoes advertised."

\subsubsection{Measures of Purchase Intention (PI)}

Purchase intention represents a surrogate indicator of actual behaviors (Fishbein \& Ajzen, 1977). Our research use 4 items to measure this purchase intention. They are "1. I will choose this pair of sports shoes rather than any other similar sports shoes." "2. I intend to buy this pair of sports shoes in the future." "3. I will possibly buy this pair of sports shoes in the future." "4. I will definitely buy this pair of sports shoes in the future" on the 7-point.

\section{Empirical Investigation}

\subsection{Pretest and Demographic Analysis Results from Main Survey}

The English version of questionnaire was translated in Chinese. Pretest was conducted by 30 graduate Chinese students to check any errors in the questionnaire, and according to the pretest results, the questionnaire was corrected. This research exploited a questionnaire survey method. We used 'WenJuanXing' site to make questionnaire in Chinese, which was loaded on WeChat and QQ to collect 275 data in total at China. We deleted the questionnaires in which participant failed to pay enough attention to this questionnaires, and 260 questionnaires were remained finally. The details of demographic figures analyzed by descriptive statistics of SPSS 22.0 were shown in Table 2.

Table 2: Demographic Analysis Results

\begin{tabular}{|c|l|c|c|}
\hline \multicolumn{2}{|c|}{ Variable } & Frequency & Percentage \\
\hline \multirow{3}{*}{ Gender } & Male & 131 & $50.4 \%$ \\
\cline { 2 - 4 } & Female & 129 & $49.6 \%$ \\
\hline \multirow{4}{*}{ Age } & Under 20 & 68 & $26.2 \%$ \\
\cline { 2 - 4 } & $21-30$ & 113 & $43.5 \%$ \\
\cline { 2 - 4 } & $31-40$ & 50 & $19.3 \%$ \\
\cline { 2 - 4 } & Over 40 & 29 & $11.2 \%$ \\
\hline \multirow{4}{*}{ Country } & Under 3000 RMB & 66 & $25.4 \%$ \\
\cline { 2 - 4 } & $3000-6000 \mathrm{RMB}$ & 109 & $41.9 \%$ \\
\cline { 2 - 4 } & $6000-10000 \mathrm{RMB}$ & 52 & $20.0 \%$ \\
\cline { 2 - 4 } & Over $10000 \mathrm{RMB}$ & 33 & $12.7 \%$ \\
\hline \multirow{3}{*}{} & China & 260 & $100 \%$ \\
\cline { 2 - 4 } & Korea & 0 & $0 \%$ \\
\cline { 2 - 4 } & Other & 0 & $0 \%$ \\
\hline \multicolumn{2}{|c|}{ Total Response } & 260 & $100 \%$ \\
\hline \multicolumn{2}{|c|}{} & & \\
\hline
\end{tabular}

\subsection{Level of Each Characteristics}

The scores of items for each of such characteristics (constructs) as congruence among multisensory cues, selfdiscrepancy awareness and object relevance between consumer and product were summed and averaged to make the participant's score level for each construct. The results of analyzing the extent to which participants felt each of the characteristics (constructs) are shown in Table 3. Each of the characteristics was perceived to be greater than midpoint (4).

\subsection{Reliability and Validity}

By calculating Cronbach's $\alpha$, we examined the internal consistency among items for each construct. The results in Table 4 where all $\alpha$ were higher than 0.9 indicated that there was a good internal consistency at every construct.

Principal component factor analysis based on Varimax rotation in SPSS 22.0 program was used to survey convergent validity. As shown in Table 4, there were six principal components consisting of the object relevance, the congruence, self-enhancing imagery, self goal-achievement emotion, purchase intention and the self-discrepancy awareness, wherein factor loading values of items indicated that all the items of each construct were judged to converge to their own construct.

Table 3: Results of Analyzing Multisensory Cues Characteristics

\begin{tabular}{|c|c|c|}
\hline CMC & SDA & RCP \\
\hline 5.18 & 5.32 & 6.38 \\
\hline
\end{tabular}


Table 4: Results of Analyzing Principal Components

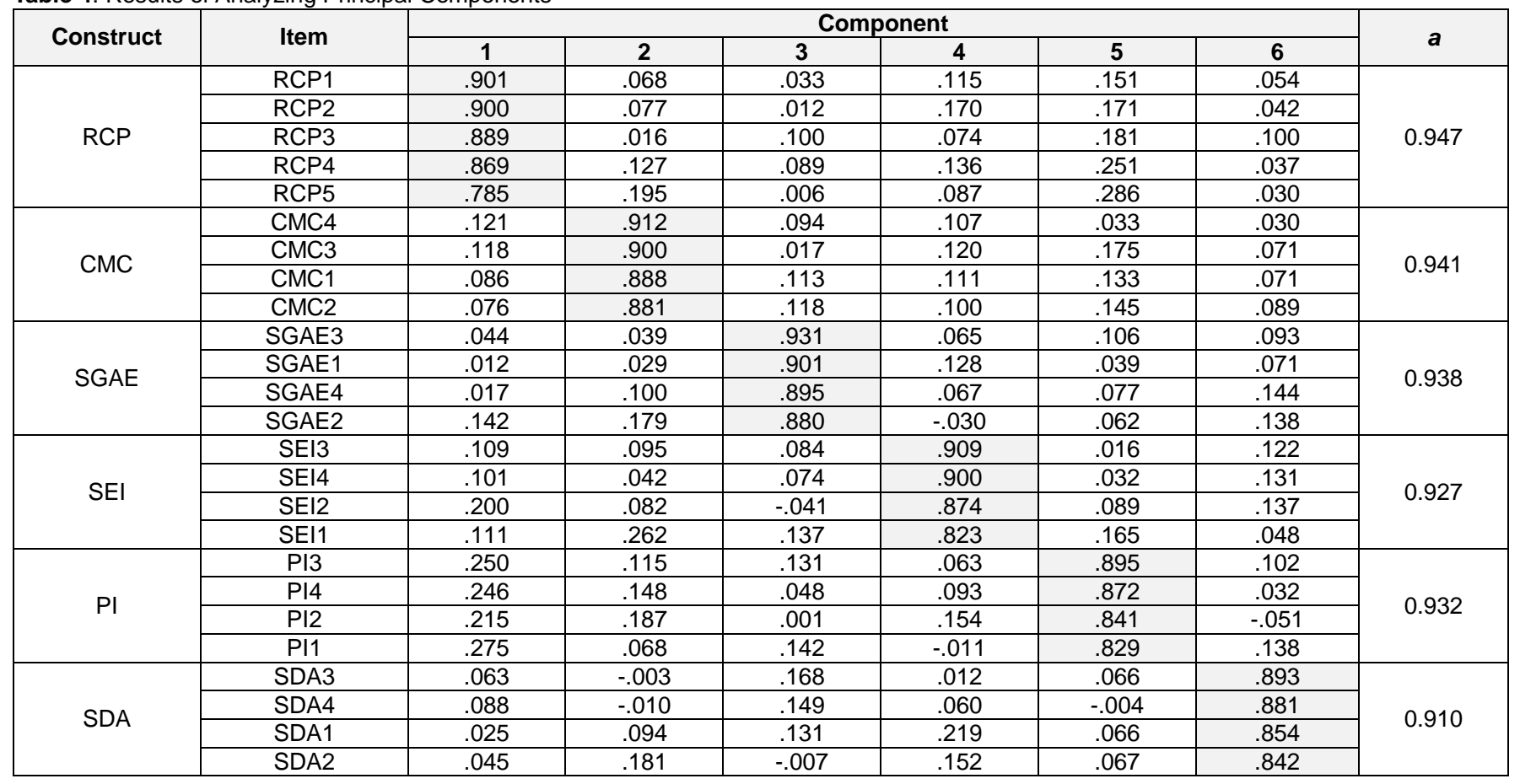

\subsection{Correlations among Constructs}

To test the discriminant validity among constructs, confirmatory factor analysis was conducted. The results of the analysis which include correlation coefficient, the squared correlation coefficients and AVE are shown in Table 5. And all the values of AVE are above 0.5, and bigger than the squared correlation coefficients respectively, which implies a good discriminant validity.

Table 5: Results of Correlations Analysis

\begin{tabular}{|l|c|c|c|c|c|c|}
\hline \multicolumn{1}{|c|}{ AVE } & CMC & SDA & RCP & SEI & SGAE & PI \\
\hline CMC & .803 & & & & & \\
\hline SDA & $\begin{array}{c}.181 \\
(.033)\end{array}$ & .718 & & & & \\
\hline RCP & $\begin{array}{r}.264 \\
(.070)\end{array}$ & $\begin{array}{r}.169 \\
(.029)\end{array}$ & .785 & & & \\
\hline SEI & $\begin{array}{l}.277 \\
(.077)\end{array}$ & $\begin{array}{c}.286 \\
(.082)\end{array}$ & $\begin{array}{c}.308 \\
(.095)\end{array}$ & .612 & & \\
\hline SGAE & .210 & .287 & .153 & .177 & & \\
$(.044)$ & $(.082)$ & $(.023)$ & $(.031)$ & .637 & \\
\hline PI & .325 & .188 & .512 & .210 & .233 & .626 \\
$(.106)$ & $(.035)$ & $(.262)$ & $(.044)$ & $(.054)$ & .62 \\
\hline
\end{tabular}

Note: the numbers of the diagonal mean AVE.

\subsection{Testing Measurement Model}

Confirmatory factor analysis in AMOS21.0 was conducted to check the convergent validity of items for each construct. As shown in Table 6, results indicated all the C.R. of items for each construct were above 2.00. The items of each construct are judged to converge with each other.
Table 6: Results of Confirmation Factor Analysis

\begin{tabular}{|c|c|c|c|c|c|}
\hline & Items & Estimate & S.E. & C.R. & $\mathbf{P}$ \\
\hline \multirow[t]{4}{*}{ CMC } & CMC1 & 1.000 & & & \\
\hline & CMC2 & .985 & .048 & 20.682 & .000 \\
\hline & CMC3 & .981 & .045 & 21.817 & .000 \\
\hline & CMC4 & 1.104 & .052 & 21.230 & .000 \\
\hline \multirow[t]{4}{*}{ SDA } & SDA1 & 1.000 & & & \\
\hline & SDA2 & .966 & .062 & 15.638 & .000 \\
\hline & SDA3 & 1.008 & .057 & 17.635 & .000 \\
\hline & SDA4 & 1.031 & .060 & 17.237 & .000 \\
\hline \multirow[t]{5}{*}{$\mathrm{RCP}$} & RCP1 & 1.000 & & & \\
\hline & RCP2 & 1.045 & .042 & 24.844 & .000 \\
\hline & RCP3 & 1.008 & .045 & 22.311 & .000 \\
\hline & RCP4 & 1.113 & .048 & 23.230 & .000 \\
\hline & RCP5 & .964 & .054 & 17.977 & .000 \\
\hline \multirow[t]{4}{*}{ SEI } & SEI1 & .942 & .053 & 17.611 & .000 \\
\hline & SEI2 & .982 & .050 & 19.577 & .000 \\
\hline & SEI3 & .987 & .042 & 23.543 & .000 \\
\hline & SEl4 & 1.000 & & & \\
\hline \multirow[t]{4}{*}{ SGAE } & SGAE1 & 1.015 & .050 & 20.143 & .000 \\
\hline & SGAE2 & .985 & .049 & 20.163 & .000 \\
\hline & SGAE3 & .978 & .041 & 23.752 & .000 \\
\hline & SGAE4 & 1.000 & & & \\
\hline \multirow[t]{4}{*}{$\mathrm{Pl}$} & $\mathrm{Pl1}$ & 1.000 & & & \\
\hline & $\mathrm{Pl} 2$ & 1.132 & .058 & 19.434 & .000 \\
\hline & $\mathrm{Pl3}$ & 1.157 & .053 & 21.981 & .000 \\
\hline & $\mathrm{Pl} 4$ & 1.105 & .064 & 17.174 & .000 \\
\hline \multicolumn{6}{|c|}{$\begin{array}{l}\mathrm{X}^{2}=617.140(\mathrm{DF}=260, \mathrm{P}=.000), \mathrm{GFI}=.804, \mathrm{AGFI}=.755, \mathrm{CFI}=.911 \\
\mathrm{TLI}=.897, \mathrm{IFI}=.912, \mathrm{RFI}=.857, \mathrm{NFI}=.876, \mathrm{RMSEA}=.091\end{array}$} \\
\hline
\end{tabular}

\subsection{Testing Hypotheses}

The results of structural equation model analysis by AMOS 21.0 program were shown in Table 7, which indicated $\quad \chi 2=617.140 \quad(\mathrm{DF}=260, \quad \mathrm{P}=.000), \quad \mathrm{GFI}=.804$, AGFI=.755, CFI=.911, TLI=.897, IFI=.912, RFI=.857, $\mathrm{NFI}=.876, \mathrm{RMSEA}=.091$. And as shown in Figure 3 and 
Table 7, all the hypotheses except $\mathrm{H} 4 \mathrm{c}$ were accepted.

Table 7: Results of Testing Hypotheses

\begin{tabular}{|c|c|c|c|c|c|c|}
\hline Hypotheses & Path & Estimate & S.E. & C.R. & P & Results \\
\hline $\mathrm{H} 1$ & $\mathrm{SEI} \rightarrow \mathrm{PI}$ & .199 & .068 & 2.912 & .004 & Accepted \\
\hline $\mathrm{H} 2$ & $\mathrm{SGAE} \rightarrow \mathrm{PI}$ & .196 & .061 & 3.232 & .001 & Accepted \\
\hline $\mathrm{H} 3 \mathrm{a}$ & $\mathrm{CMC} \rightarrow \mathrm{SEI}$ & .177 & .062 & 2.842 & .004 & Accepted \\
\hline $\mathrm{H} 3 \mathrm{~b}$ & $\mathrm{SDA} \rightarrow \mathrm{SEI}$ & .238 & .070 & 3.386 & .000 & Accepted \\
\hline $\mathrm{H} 3 \mathrm{c}$ & $\mathrm{PCR} \rightarrow \mathrm{SEI}$ & .232 & .064 & 3.636 & .000 & Accepted \\
\hline $\mathrm{H} 4 \mathrm{a}$ & $\mathrm{CMC} \rightarrow \mathrm{SGAE}$ & .163 & .072 & 2.264 & .024 & Accepted \\
\hline $\mathrm{H} 4 \mathrm{~b}$ & $\mathrm{SDA} \rightarrow \mathrm{SGAE}$ & .309 & .082 & 3.773 & .000 & Accepted \\
\hline $\mathrm{H} 4 \mathrm{C}$ & $\mathrm{RCP} \rightarrow \mathrm{SGAE}$ & .086 & .073 & 1.174 & .240 & Unaccepted \\
\hline $\mathrm{X}^{2}=617.140(\mathrm{DF}=260, \mathrm{P}=.000), \mathrm{GFI}=.804, \mathrm{AGFI}=.755, \mathrm{CFI}=.911, \mathrm{TLI}=.897, \mathrm{IFI}=.912, \mathrm{RFI}=.857, \mathrm{NFI}=.876, \mathrm{RMSEA}=.091$ \\
\end{tabular}

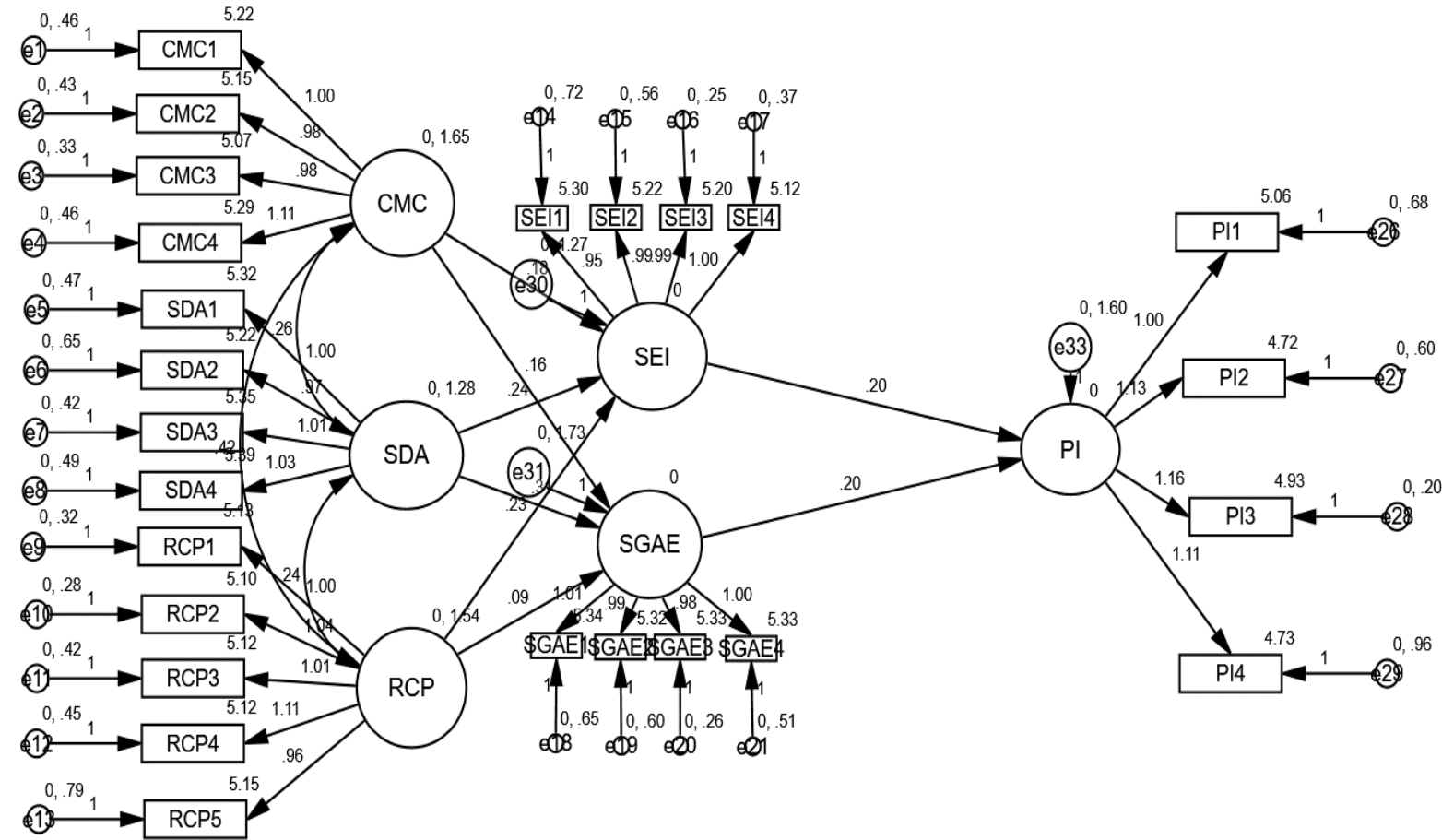

Figure 3: Results of Testing Hypotheses

\section{General Discussion}

\subsection{Research Summary}

In our study, we explored the effect of characteristics perceived at multisensory cues such as congruency between multisensory cues, self-discrepancy awareness, and object relevance between consumers and products advertised on purchase intention. We used advertisement including both of visual and auditory sensory cues for making consumers feel congruency between the visual and the auditory aspects of the advertising. And the external multisensory cues were used, to also help consumers aware the gap between the actual self and the ideal self, furthermore, and to help them feel object relevance between the identity of the product and their own ideal self. This study developed hypotheses about, and tested, the roles of the self-enhancing imagery and self goal-achievement emotion in the effects of each of the three characteristics of the multisensory cues on purchase intention. The study results are summarized as followings.

First, both of the self-enhancing imagery and self goalachievement emotion positively affect consumers' purchase intention. Second, the congruency between multisensory cues has a positive effect on activating consumers' selfenhancing imagery and feeling self goal-achievement emotion. Third, the self-discrepancy awareness plays positive roles in activating the self-enhancing imagery and feeling the self goal-achievement emotion. Fourth, the 
object relevance between the consumer and the product advertised can activate only the self-enhancing imagery. The object relevance doesn't trigger the consumers' goalachievement emotion.

The object relevance is a variable approached in view of rational thought. That is, when consumers are exposed to a brand, the first thing that comes to their mind might be whether the brand can be lined together with them in view of the congruence between their identity and the image of the brand (Reed, 2004). However, goal-achievement emotion is a concept including more consummatory emotional goal. This may be the reason why this hypothesis was rejected.

\subsection{Theoretical and Managerial Implication}

Although previous studies had examined the effects of single sensory cues on consumer purchase intentions, they have rarely explored multisensory cues' effects. Based on the relevant theories of integrated marketing and design, we conducted systematic research. This study explored whether the three (two) characteristics of the multisensory cues affect the self-enhancing imagery (self goal-achievement emotion) which could have positive impacts on purchase intention. Therefore, the results of this study can contribute to the advancement of theory about the effects of the multisensory cues on purchase intention.

This research mainly studied the application of multisensory cues to advertising in view of three characteristics of multisensory cues. Therefore it can suggest managerial implications as followings.

First, this research found the evidences that both selfenhancing imagery and self goal-achievement emotions positively affect purchase intention. Based on these, marketers should focus on how to enhance consumers' self imageries and how to arouse their goal-achievement emotion when developing advertisement.

Second, marketers should pay attention to multisensory cues' characteristics such as the congruency between multisensory cues, self-discrepancy awareness and object relevance between consumers and products advertised which can be perceived by consumers, to enhance the self imageries and to feel the goal-achievement emotion, when developing advertisement.

\subsection{Limitations and Directions for Future Intention}

There are several limitations in this research that can be studied in the future.

Firstly, this research just studied three characteristics of multisensory cues and did not demonstrate how the five cue modalities interact with each other. The relationship among five cues modalities, and more characteristics perceived at the time of being exposed to the advertisement using the multisensory cues (Feng \& Lee, 2015) can be studied in the future.

Secondly, this research mentioned just self goalachievement emotion positively affects purchase intention, but did not study the arousal level of the emotion. Therefore, whether the level of the emotion arousal will affect purchase intention can be studied in the future research.

Finally, the survey was just conducted in China, so we did not fully exonerate the culture that may influence consumers' purchase intention when variety of multisensory cues are used for advertising. This can be the subject for future research.

\section{References}

Atakan, S. S. (2014). Consumer response to product construction: The role of haptic stimulation. International Journal of Consumer Studies, 38(6), 586-592.

Bargh, J. A. (1997). Nonconscious behavioral confirmation processes: The self-fulfilling consequences of automatic stereotype activation. Journal of Experimental Social Psychology, 33(5), 541-560.

Belk, R. W. (1988). Possessions and the extended self. Journal of Consumer Research, 15(2), 139-168.

Biggers, T., \& Pryer, B. (1982). Attitude change: A function of emotion-eliciting qualities of environment. Personality and Social Psychology Bulletin, 8(1), 94-99.

Bone, P. F., \& Ellen, P. S. (1999). Scents in the marketplace: Explaining a fraction of olfaction. Journal of Retailing, 75(2), 243-262.

Bresciani, J. P., Ernst, M. O., Drewing, K., Bouyer, G., Maury, V., \& Kheddar, A. (2005). Feeling what you hear: Auditory signals can modulate tactile tap perception. Experimental Brain Research, 162(2), 172-180.

Chartrand, T. L., \& Bargh, J. A. (1996). Automatic activation of impression formation and memorization goals: Nonconscious goal priming reproduces effects of explicit task instructions. Journal of Personality and Social Psychology, 71(3), 464-478.

Cheng, F. F., Wu, C. S., \& Yen, D. C. (2009). The effect of online store atmosphere on consumer's emotional responses: An experimental study of music and colour. Behaviour \& Information Technology, 28(4), 323-334.

Choi, N.-H., Nguyen, Q. M., \& Teng, Z. (2019). Effects of performance, imagery and regulatory focus on customer engagement. Journal of Distribution Science, 17(1), 57 72.

Choi, N.-H., Zhang, J.-L., \& Chen, C. (2018). Store's visual sensory cues, emotion, and reusage intention. Journal of Distribution Science, 16(2), 35-45.

De Gelder, B., \& Bertelson, P. (2003). Multisensory integration, perception and ecological validity. Trends in Cognitive Sciences, 7(10), 460-467.

DeWall, C. N., Baumeister, R. F., Chester, D. S., \& Bushman, B. J. (2016). How often does currently felt emotion predict social behavior and judgment? A meta- 
analytic test of two theories. Emotion Review, 8(2), 136143.

Driver, J., \& Noesselt, T. (2008). Multisensory interplay reveals cross modal influences on 'sensory-specific' brain regions, neural responses, and judgments. Neuron, 57(1), 11-23.

Elliot, A. J., \& Pekrun, R. (2007). Emotion in the hierarchical model of approach-avoidance achievement motivation. In P. A. Schutz, \& R. Pekrun (Eds.), Emotion in education (pp.57-73), San Diego, CA: Academic Press.

Dweck, C. S., \& Elliot, E. (1988). Goals: An approach to motivation and achievement. Journal of Personality and Social Psychology, 54(1), 5-12.

Feng, Z., \& Lee, U.-K. (2015). The effect of online elements on consumer purchase intention: Insights from a Taobao perspective. Journal of Distribution Science, 13(5), 1522.

Fishbach, A., Friedman, R. S., \& Kruglanski, A. W. (2003). Leading us not into temptation: Momentary allurements elicit overriding goal activation. Journal of Personality and Social Psychology, 84(2), 296-309.

Fishbein, M., \& Ajzen, I. (1977). Belief, attitude, intention, and behavior: An introduction to theory and research. Philosophy and Rhetoric, 10(2), 130-132.

Franz, G. (2006). Space, color, and perceived qualities of indoor environments. In A. Abdel-Hadi, M. K. Tolba, \& $\mathrm{S}$. Soliman (Eds.), In environment, health and sustainable development proceedings (IAPS 19) (pp.1-8), Seattle, CA: Hogrefe Huber Press.

Gottfried, J. A., \& Dolan, R. J. (2004). Human orbitofrontal cortex mediates extinction learning while accessing conditioned representations of value. Nature Neuroscience, 7(10), 1144-1152.

Helbig, H. B., \& Ernst, M. O. (2008). Visual-haptic cue weighting is independent of modality-specific attention. Journal of Vision, 8(1), 1-16.

Higgins, E. T. (1987). Self-discrepancy: A theory relating self and affect. Psychological Review, 94(3), 319-340.

Holbrook, M. B. (1992). Patterns, personalities, and complex relationships in the effects of self on mundane everyday consumption: These are 495 of my most and least favorite things. Advances in Consumer Research, 19(1), 417-423.

Hulleman, C. S., Schrager, S. M., Bodmann, S. M., \& Harackiewicz, J. M. (2010). A meta-analytic review of achievement goal measures: Different labels for the same constructs or different constructs with similar labels? Psychological Bulletin, 136(3), 422-423.

Hultén, B. (2012). Sensory cues and shoppers' touching behaviour: The case of IKEA. International Journal of Retail \& Distribution Management, 40(4), 273-289.

Imschloss, M., \& Kuehnl, C. (2017). Don't ignore the floor: Exploring multisensory atmospheric congruence between music and flooring in a retail environment. Psychology \& Marketing, 34(10), 931-945.

Jones, M. A. (1999). Entertaining shopping experiences: An exploratory investigation. Journal of Retailing and Consumer Services, 6(3), 129-139.

Jones, M. A., Reynolds, K. E., \& Arnold, M. J. (2006). Hedonic and utilitarian shopping value: Investigating differential effects on retail outcomes. Journal of Business Research, 59(9), 974-981.

Kleine III, R. E., Kleine, S. S., \& Kernan, J. B. (1993). Mundane consumption and the self: A social-identity perspective. Journal of Consumer Psychology, 2(3), 209235.

Krishna, A. (2012). An integrative review of sensory marketing: Engaging the senses to affect perception, judgment and behavior. Journal of Consumer Psychology, 22(3), 332-351.

Kruglanski, A. W. (1996). Goals as knowledge structures. In P. M. Gollwitzer, \& J. A. Bargh (Eds.), The psychology of action: Linking cognition and motivation to behavior(pp.599-618), New York, NY: Guilford Press.

Lalanne, C., \& Lorenceau, J. (2004). Crossmodal integration for perception and action. Journal of Physiology-Paris, 98(1-3), 265-279.

Laroche, M., \& Sadokierski, R. (1994). Role of confidence in a multi-brand model of intentions for a highinvolvement service. Journal of Business Research, 29(1), 1-12.

Ludden, G. D., Schifferstein, H. N., \& Hekkert, P. (2009). Visual-tactual incongruities in products as sources of surprise. Empirical Studies of the Arts, 27(1), 61-87.

Lin, I. Y. (2004). Evaluating a servicescape: The effect of cognition and emotion. International Journal of Hospitality Marketing, 23(2), 163-178.

MacInnis, D. J., \& Price, L. L. (1987). The role of imagery in information processing: Review and extensions. Journal of Consumer Research, 13(4), 473-491.

Macpherson, F. (2011). Individuating the senses. In F. Macherson (ed.), The senses: Classical and contemporary readings (pp.3-46), London, UK: Oxford University Press.

Mason, T. B., Smith, K. E., Engwall, A., Lass, A., Mead, M., Sorby, M., \& Wonderlich, S. (2019). Self-discrepancy theory as a transdiagnostic framework: A meta-analysis of self-discrepancy and psychopathology. Psychological Bulletin, 145(4), 372-389.

Mattila, A. S., \& Wirtz, J. (2001). Congruency of scent and music as a driver of in-store evaluations and behavior. Journal of Retailing, 77(2), 273-289.

Mehrabian, A., \& Russell, J. A. (1974). An approach to environmental psychology. Cambridge, US: The MIT Press.

Michon, R., Chebat, J. C., \& Turley, L. W. (2005). Mall atmospherics: The interaction effects of the mall environment on shopping behavior. Journal of Business Research, 58(5), 576-583.

Morinez, C., Kube, J., Santos, H., Da Costa, M. S., \& Antranikian, G. (2007). High yield of mannosylglycerate production by upshock fermentation and bacterial milking of trehalose-deficient mutant thermus 
thermophilus RQ-1. Applied Microbiology and Biotechnology, 75(5), 1039-1045.

Müller, V. I., Habel, U., Derntl, B., Schneider, F., Zilles, K., Turetsky, B. I., \& Eickhoff, S. B. (2011). Incongruence effects in crossmodal emotional integration. Neuroimage, 54(3), 2257-2266.

Orellana-Damacela, L. E., Tindale, T. S., \& Suarez-Balcazar, Y. (2000). Decisional and behavioral procrastination: How they relate to self-discrepancies. Journal of Social Behavior and Personality, 15(5), 225-238.

Panwar, D., Anand, S., Ali, F., \& Singal, K. (2019). Consumer decision making process models and their applications to market strategy. International Management Review, 15(1), 36-44.

Pekrun, R. (2006). The control-value theory of achievement emotions: Assumptions, corollaries, and implications for educational research and practice. Educational Psychology Review, 18(4), 315-341.

Pekrun, R., Elliot, A. J., \& Maier, M. A. (2006). Achievement goals and discrete achievement emotions: A theoretical model and prospective test. Journal of Educational Psychology, 98(3), 583-597.

Pekrun, R., Elliot, A. J., \& Maier, M. A. (2009). Achievement goals and achievement emotions: Testing a model of their joint relations with academic performance. Journal of Educational Psychology, 101(1), 115-135.

Peracchio, L. A., \& Tybout, A. M. (1996). The moderating role of prior knowledge in schema-based product evaluation. Journal of Consumer Research, 23(3), 177192.

Petrova, P. K., \& Cialdini, R. B. (2008). Evoking the imagination as a strategy of influence. In C. P. Haugtvedt, P. M. Herr, \& F. R. Kardes (Eds.), Handbook of consumer psychology (pp.505-524), New York, NY: Psychology Press.

Philippot, P., Dethier, V., Baeyens, C., \& Bouvard, M. (2018). Validation of the Self-Discrepancies Scale (SDS). A tool to investigate the self in clinical and research settings. Revue Européenne de Psychologie Appliquée, 68(2), 69-77.

Pourtois, G., Schwartz, S., Seghier, M. L., Scherer, K. R., \& Vuilleumier, P. (2005). The voices of wrath: Brain responses to angry prosody in meaningless speech. Nature Neuroscience, 8(2), 145-146.

Ratneshwar, S., \& Morrin, M. (2000). The impact of ambient scent on evaluation, attention, and memory for familiar and unfamiliar brands. Journal of Business Research, 49(2), 157-165.

Reed, A. (2004). Activating the self-importance of consumer selves: Exploring identity salience effects on judgments. Journal of Consumer Research, 31(2), 286-295.
Rossiter, J. R., \& Percy, L. (1978). Visual imaging ability as a mediator of advertising response. Advances in Consumer Research, 5(1), 621-629.

Rossiter, J. R., \& Percy, L. (1983). Effects of picture size and color on brand attitude responses in print advertising. Advances in Consumer Research, 10(1), 17-20.

Scherer, K. R. (2000). Psychological models of emotion. The Neuropsychology of Emotion, 137(3), 137-162.

Schlosser, A. E. (2003). Experiencing products in the virtual world: The role of goal and imagery in influencing attitudes versus purchase intentions. Journal of Consumer Research, 30(2), 184-198.

Seigneuric, A., Durand, K., Jiang, T., Baudouin, J. Y., \& Schaal, B. (2010). The nose tells it to the eyes: Crossmodal associations between olfaction and vision. Perception, 39(11), 1541-1554.

Shah, H., Aziz, A., Jaffari, A. R., Waris, S., Ejaz, W., Fatima, M., \& Sherazi, K. (2012). The impact of brands on consumer purchase intentions. Asian Journal of Business Management, 4(2), 105-110.

Shimojo, S., \& Shams, L. (2001). Sensory modalities are not separate modalities: Plasticity and interactions. Current Opinion in Neurobiology, 11(4), 505-509.

Shiv, B., \& Huber, J. (2000). The impact of anticipating satisfaction on consumer choice. Journal of Consumer Research, 27(2), 202-216.

Sirgy, M. J. (1982). Self-concept in consumer behavior: A critical review. Journal of Consumer Research, 9(3), 287-300.

Stokburger-Sauer, N., Ratneshwar, S., \& Sen, S. (2012). Drivers of consumer-brand identification. International Journal of Research in Marketing, 29(4), 406-418.

Thapa, A. (2011). Cyber stalking: Crime and challenge at the cyber space. An International Journal of Engineering Sciences, 2(1), 340-354.

Thesen, T., Vibell, J. F., Calvert, G. A., \& Österbauer, R. A. (2004). Neuroimaging of multisensory processing in vision, audition, touch, and olfaction. Cognitive Processing, 5(2), 84-93.

Turley, L. W., \& Milliman, R. E. (2000). Atmospheric effects on shopping behavior: A review of the experimental evidence. Journal of Business Research, 49(2), 193-211.

Wallendorf, M., \& Arnould, E. J. (1988). My favorite things: A cross-cultural inquiry into object attachment, possessiveness, and social linkage. Journal of Consumer Research, 14(4), 531-547.

Zinkhan, G. M., \& Hong, J. W. (1991). Self concept and advertising effectiveness: A conceptual model of congruency conspicuousness, and response mode. Advances in Consumer Research, 18(1), 348-354. 